\title{
Where Does It Hurt?
}

\author{
Cathy Busby
}

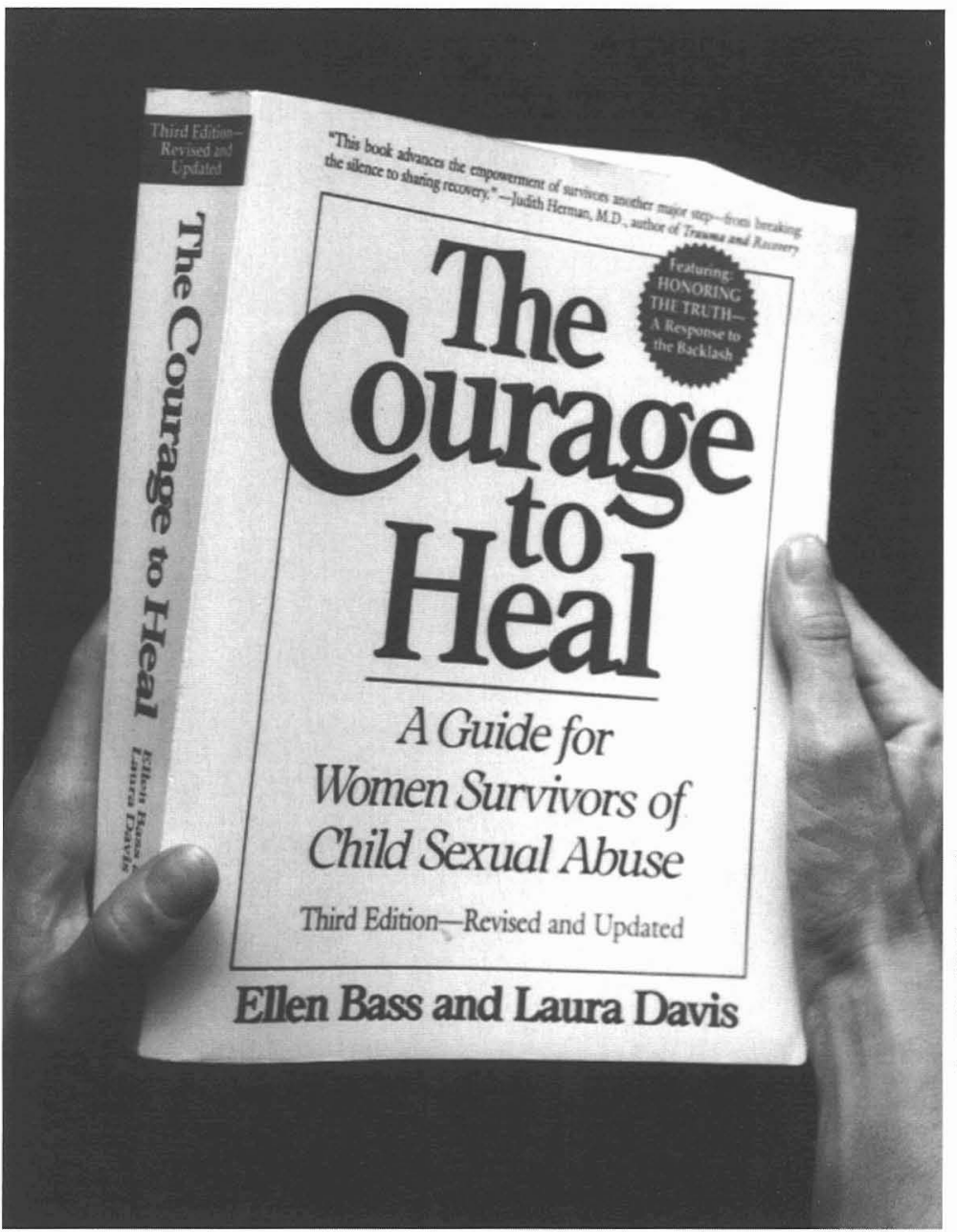

The Courage to Heal is the most influential book available on the subject of women and sexual abuse. The 1994 revised and updated third edition is a bulky 604 pages resembling a text-book, a user-friendly manual offering a pragmatic course in healing to the reader. The extensive collection of testimonials is intended to help the reader identify herself within a community of survivors.

These images are excerpted from the essay, "The Lure of Roseanne's Autopathography and Survivor Identity," forthcoming in When Pain Strikes (Burn, Busby and Sawchuk, eds., University of Minnesota Press and the Banff Centre, 1998). 


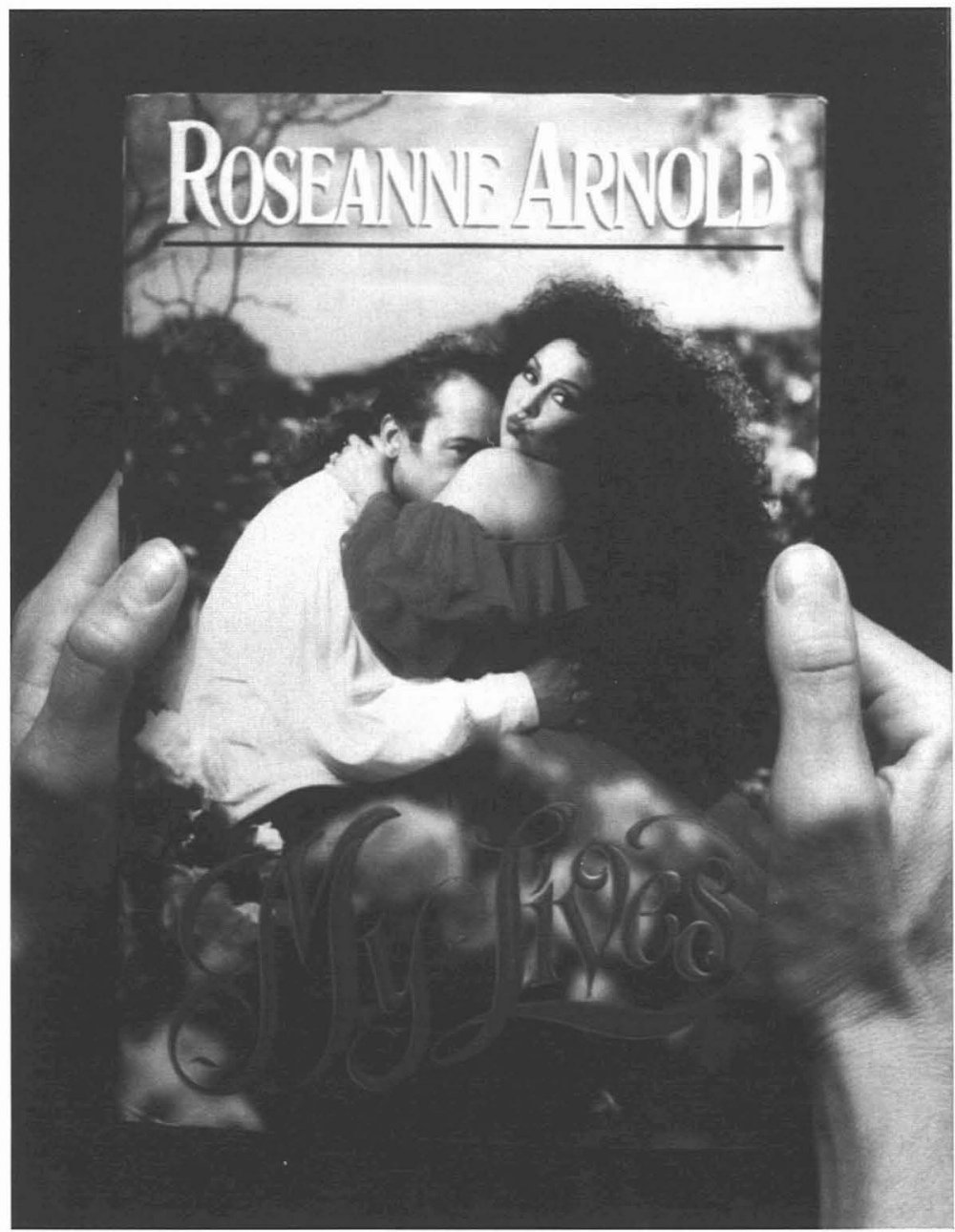

The cover of My Lives suggests a mass-market romance novel with the author, Roseanne, photographed in a free-wheeling, sexy, gypsy fantasy of romanticized pleasure. In contrast to the dust-jacket, the contents describe her struggle to live and overcome her depression and self-abuse. She talks about the profound depth of injury she attributes to abuse by her parents, and claims feminism helped her to be angry and disgusted at the victimization of women and children.

The Courage to Heal earnestly coaches its readers toward step-by-step improvement. My Lives reveals chaotic emotions and recurring dysfunction nothing can make it better. 

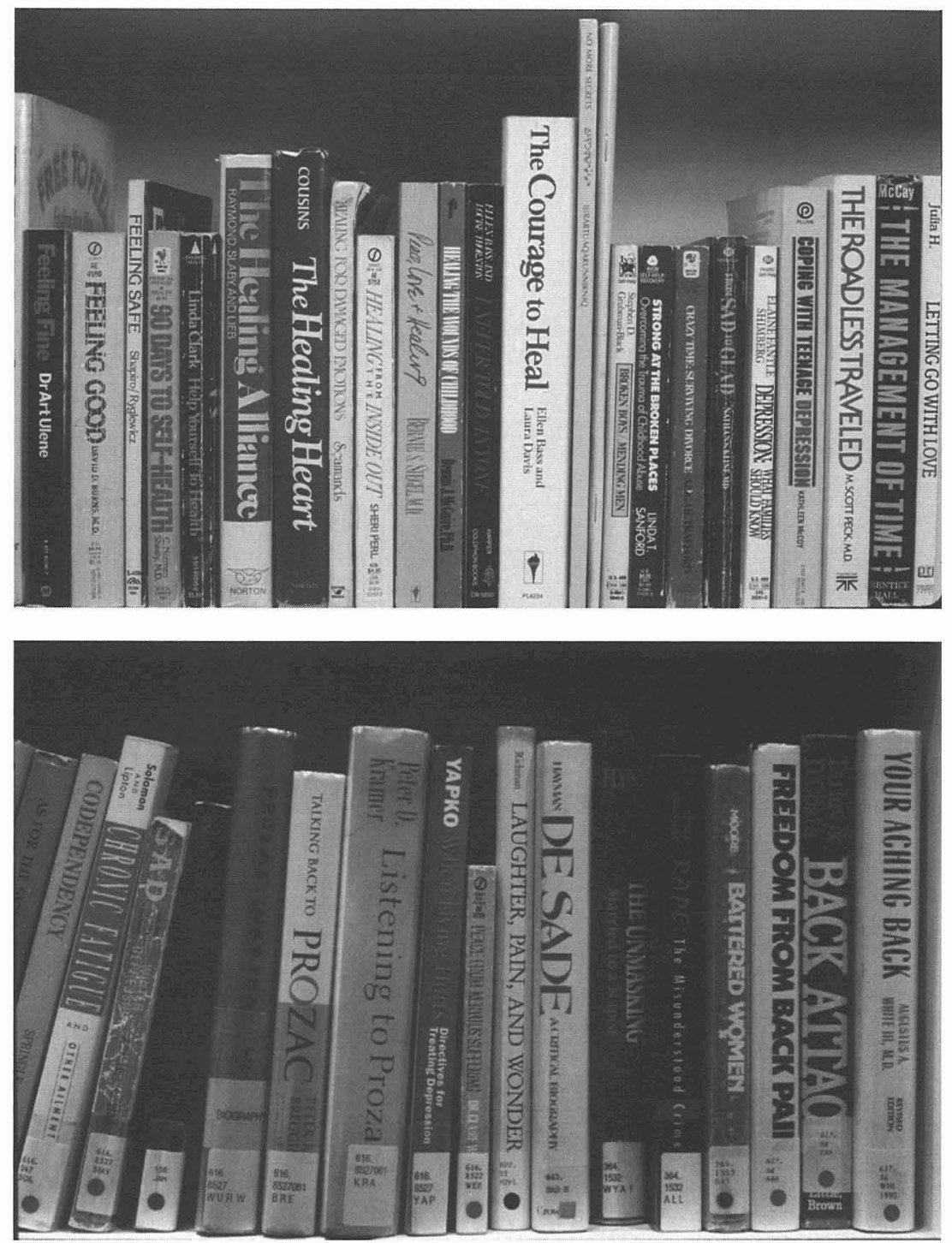

Walter Phillips Gallery, The Banff Centre, Sept.1996, installation. 